\title{
Subject Review: Brain Tumor Classification using Neural Network
}

\author{
Kawther Thabt Saleh ${ }^{1}$, Iman Hussein AL-Qinani ${ }^{2}$, Nisreen Abd Alhadi Jabr ${ }^{3}$ \\ ${ }^{1,2}$ Lecturer, Department of Computer Science, College of Education, Mustansiriyah University \\ Baghdad - Iraq \\ ${ }^{3}$ Assistant Lecturer, Branch of Teams Games, College of Physical Education and Sports Science \\ Mustansiriyah University, Baghdad - Iraq
}

\begin{abstract}
The basic goal of this research study is to show a critical review of existing paper on human brain tumor classification systems above the last 10 years. Attention and study accomplishments in brain tumor classification have arisen essentially above the previous few years, particularly with the need for an assistant to the doctor to diagnose such critical non-faulty diseases has led to the building of this type of system, for instance neural networks is important compounds. Survey and evaluation become necessary, as the number of suggested techniques increases.

This study present the survey focus on various researchers applied their systems using neural network, and moreover a contrast between these systems is discussed.
\end{abstract}

Key Words: Brain Tumor, Feature Extraction, Artificial Neural Network (ANN), Magnetic Resonance Imaging (MRI), Computer Aided Diagnosis system (CAD).

\section{INTRODUCTION}

Brain tumor kills many people, so it is considered one of the dangerous diseases. Tumor is the disorderly grew of tissue in any side of the body. For this reason, makes many researchers to build a system that helps doctors in their work to diagnose this type of disease. Although there are many challenges, including the accuracy of diagnosis system and whether this tumor is benign or malignant, there are also some applications that work to diagnose the type of brain tumor and according to several measures the system has been built upon. In this case, doctors use positron emission tomography (PET) or magnetic resonance imaging (MRI) to diagnose the brain in the first step.

An attractive characteristic of MRI is that it is simple to obtain distinct contrasts between kinds of tissue (Data from a multispectral image of the same subject). In last years, MRI become the technology growing in popularity for the survey of humanity brain. That noninvasive technicality could supply spatial images of highly decision and its rich purport of information could have adequately used for build automated diagnostic material, that could allow the medical order to sketch faster and easier conclusions on the case of the brain beneath search [1].

The ANN is a branch of AI and has been recognized in computer science as a new technology. A 'hot' research field in medicine is currently Neural Networks. In many areas, such as education, industry, it has a huge application; in the decision support system [2], in medical matters the Neural Network plays an important role, engineering and manufacturing.

In several medical imaging applications, a significant role is also played by the Artificial Neural Network (ANN). The diagnosis of cancer ANN is used by cells to distinguish regular and dysfunctional cells in different organ of body region. In this study, we will presentation survey focus on various researchers used the artificial neural networks as a brain cancer disease diagnosis system.

In recent years, proposed many of approaches for building brain cancer disease diagnosis system to aid the doctors. In this review, we work ways an analysis of brain cancer disease diagnosis method that depend on ANN. The remainder of this study paper was 
arranged as follows: In part two the literary survey of certain charts that proposed in the last convention comparison analytics of the maps in part three that were mentioned in part two. Lastly, in section four, the conclusions are shown.

\section{LITERATURE SURVEY}

Historically, several working approaches have been reviewed with respect to the identification of brain tumors. We present some of these researches in this section.

Georgiadis et al. (2011) suggested the mix of formative and spectral analysis data from meningioma and MRI metastasis would progress the accuracy, of discrimination in pattern recognition systems designed to provide clinicians with a valuable second opinion instrument [3].

Dahab et al. (2012) by using MRI scans aim Carrying out an automatic classification of brain tumors, an updated PNN model based on LVQ with data and image processing and manipulate methods is suggested. In terms of training efficiency, classification accuracy, and the evaluation, computational time of the modified PNN classifier performance is assessed [4].

Sumitra and Rakesh (2013) presented the Brain tumor classification scheme, Extraction, reduction of dimensionality, and classification were used. The characteristics obtained from magnetic resonance imaging (MRI) were reduce use PCA for was important characteristics like mean, median, variance, correlation, maximum and minimum density values. In classification process, the Backpropagation Neural Network-based classifier was made. In order to identify topics as standard, benign and malicious brain tumor pictures, this classifier was used. The findings show that the Backpropagation Neural Network classifier offers fast and precise classification as opposed to other $\mathrm{NN}$ and can be used effective to identify brain tumors with a high degree of precision [5].

Swapnali and Dimple (2014) use the new method of brain tumor classification, this work is the mixture of Key Component Analysis, Discrete Wavelet Transform, and Neural Probabilistic Network. An effective Brain Tumor Classification system is developed with a maximum recognition rate of $100 \%$ by using this algorithm. This approach could help in the precise diagnosis of Brain Tumor classification [6].

Pan et al. (2015) use the grading processes were developed based on the classification of brain tumors depend on the CNN deep learning structure. The findings indicate a maximum 18 percent increase in CNN's grading efficiency-based sensitivity and specificity relative to neural network. Kernel perceptions and performance outcomes at various layers show that, the learned kernels could closely resemble a tumor function. they have found, however, that the more difficult structure of CNN not surpass the findings of simple structured CNNs [7].

T. Liu et al. (2016) aim to use the LVQ neural network, that is classically utilized for recognition the pattern. A normal diagnostic precision of (85.7) percent and a glioma diagnostic precision of (89.5) percent had been achieved by applying a proposed procedure. A recent approach to excavating Raman spectrum data is the LVQ neural network. In addition, it is speedy and easy, don't require the high counterpart of the spectra, and investigating a reasonably high accuracy. It could be employed to prognosticate brain tumors and to help enhance the cutting edges of the gliomas [8].

Rani and Vashisth (2017) present work, the morphological and thresholding methods of statistical analysis are used to process the images collected by MRI. To classify the output of tumors part of the picture, the feedforward backprop neural network is used. This technique results in high precision and less detection of iterations, which further decreases the consumption time [9].

Heba et al. (2018) presented an efficiency system that collects DWT and DNN categorize brain MRIs into three types of malicious, normal and brain tumors: Glioblastoma, bronchogenic metastatic carcinoma and sarcoma, respectively. The novel technique construction is similar to the architecture of coevolutionary neural networks (CNN), but needs least hardware requirements and requires a comfortable processing time for big size images $256 \times 256$. In comparison, relative to conventional classifiers, the use of the DNN classifier demonstrates high precision. In the future, the positive results obtained using the DWT could be used for CNN and the outcomes could be compared [10].

jaswini et al. (2019) proposed The Adaptive Regularized Kernel relies on Fuzzy C-Means Clustering (ARKFCM) for segmentation in the brain tumor classification system. For the identification and brain tumor classifications depend on extracted characteristics, a composition of the SVM and the ANN is offered. In order to the validation of the proposed process, a data set of 94 images is considered to result in an accuracy ratio of 91.4 percent, a sensitivity of 98 percent, a precision of 78 percent and an average of bit error of 0.12 . There is a contrast between the suggested approach with other traditional approaches and the results are tabulated [11]. 
Fatih and Derya (2020) proposed Brain tumor classification system. In this research, brain tumor discovery depends on FCM with SR and CNN and exciting learning machine systems (Super Resolution - Fuzzy C-Means - Convolutional Neural Networks) method has made. The objective of this research was to segment high-performance tumors using the (SR-FCM) method for the detection of tumors from brain MRI. Feature extraction and pre-trained SqueezeNet structure from (CNN) structures and ELM classification processes have been subsequently executed. It was determined in empirical studies that brain tumors were improve segmentation and extracted using the Super Resolution and Fuzzy C-Means process. Features from a smaller NN type with fewer parameters were extracted using a SquezeeNet architecture. In the proposed procedure, the diagnosis of segmented brain tumors using SR-FCM was detected at a 98.33 percent accuracy rate. This prevalence is 10 percent higher than the average of identification without SR of brain tumors segmentation processing with FCM [12].

\section{SCHEMES' COMPARATIVE STUDY}

The comparison between the previous systems is shown in table 1 below.

Table1. Analytical comparison of the schemes for several dataset

\begin{tabular}{|c|l|l|c|c|}
\hline Reference & \multicolumn{1}{|c|}{ Dataset } & Features Extraction & $\begin{array}{c}\text { Accuracy } \\
\text { ratio \% }\end{array}$ & $\begin{array}{c}\text { Classification } \\
\text { Method }\end{array}$ \\
\hline$[3]$ & Created Database & $\begin{array}{l}\text { Combination of textural } \\
\text { and spectroscopic } \\
\text { features }\end{array}$ & $92.15 \%$ & $\begin{array}{c}\text { Support Vector } \\
\text { Machines (SVMs) }\end{array}$ \\
\hline$[4]$ & Created Database & $\begin{array}{l}\text { Feature vectors } \\
\text { extraction and reduction } \\
\text { process }\end{array}$ & $\begin{array}{l}\% 79 \\
\text { Probabilistic Neural } \\
\text { Network (PNN) }\end{array}$ \\
\hline$[5]$ & $\begin{array}{l}\text { collection database } \\
\text { from open-source } \\
\text { database and a few } \\
\text { hospitals }\end{array}$ & $\begin{array}{l}\text { Principles Component } \\
\text { Analysis (PCA) }\end{array}$ & $\begin{array}{l}\text { Accuracy from } \\
100 \% \text { to 73\% }\end{array}$ & $\begin{array}{c}\text { Back Propagation } \\
\text { Network }\end{array}$ \\
\hline$[6]$ & Created Database & $\begin{array}{l}\text { Discrete Wavelet } \\
\text { (DWT), Grey Level Co- } \\
\text { occurrence Matrix } \\
\text { (GLCM) Transform and } \\
\text { Principal Component } \\
\text { Analysis (PCA) }\end{array}$ & $100 \%$ & $\begin{array}{c}\text { Probabilistic Neural } \\
\text { Network }\end{array}$ \\
\hline
\end{tabular}

\begin{tabular}{|c|c|c|c|c|}
\hline Reference & Dataset & Features Extraction & $\begin{array}{c}\text { Accuracy } \\
\text { ratio \% }\end{array}$ & $\begin{array}{c}\text { Classification } \\
\text { Method }\end{array}$ \\
\hline$[7]$ & BRATS 2014 & $\begin{array}{l}\text { Select data between high- } \\
\text { labeled (Class one) and } \\
\text { low-grade (Class two) } \\
\text { tumors }\end{array}$ & $\begin{array}{c}\text { Convolutional } \\
\text { Neural Networks } \\
\text { (CNN) }\end{array}$ \\
\hline$[8]$ & $\begin{array}{l}\text { A Raman confocal } \\
\text { microlaser } \\
\text { spectroscope with } \\
785 \text { nm in vitro } \\
\text { excitation was used } \\
\text { to record the Raman } \\
\text { tissue spectrum of 20 } \\
\text { brain tumor patients. }\end{array}$ & $\begin{array}{l}\text { PCA, linear discriminant } \\
\text { analysis, and SVM }\end{array}$ & $89.5 \%$ & $\begin{array}{c}\text { Luantization (LVQ) } \\
\text { Neural Network }\end{array}$ \\
\hline
\end{tabular}


International Journal of Advances in Scientific Research and Engineering (ijasre), Vol 7 (9), September -2021

\begin{tabular}{|c|c|c|c|c|}
\hline [9] & $\begin{array}{l}\text { MRI dataset is } \\
\text { collected from the } \\
\text { Harvard medical } \\
\text { school architecture } \\
\text { and some data are } \\
\text { gathered from civil } \\
\text { hospital of Haryana. }\end{array}$ & $\begin{array}{c}\text { Principle Component } \\
\text { Analysis ( PCA) }\end{array}$ & $99.2 \%$ & $\begin{array}{c}\text { Feed-Forward } \\
\text { Propagation Neural } \\
\text { Network }\end{array}$ \\
\hline [10] & $\begin{array}{l}\text { Created Database } \\
\text { collected from } \\
\text { Harvard Medical } \\
\text { School }\end{array}$ & DWT and PCA & $96.97 \%$ & $\begin{array}{c}\text { Deep Neural } \\
\text { Network (DNN) }\end{array}$ \\
\hline [11] & Created Database & $\begin{array}{l}\text { Region based statistic } \\
\text { features and Region } \\
\text { Property based Statistic } \\
\text { Features }\end{array}$ & $91.4 \%$ & ANN and SVM \\
\hline [12] & TCGA-GBM & Squeeze Net CNN & $98.33 \%$ & ELM \\
\hline
\end{tabular}

\section{CONCLUSION}

In this study, it has been reviewed a number of methods for brain tumor classification system be based on neural network within the duration (2011-2020). Computer Aided Diagnosis (CAD) application become actual important medical problem specially to aid doctors. These diagnosis systems are studied and analyses entirely to rise the powerfully of the classification methods and for guarantee the resolve if the individual has any health problem. The outline of this study, every these the techniques are useful for human brain tumor classification. All systems are unparalleled in it is private method, that may be useful for diverse applications. Currently, the brain tumor classification technology is growth so the speedy and safe traditional classification technology that will continuously achieve a on top of classification rate. Recently, proposed human brain tumor classification methods also raise diagnosis the correct case by present more than ANN for human brain tumor classification algorithms. Every system has some of advantages and drawbacks and so new systems have been advanced.

\section{REFERENCES}

[1] E.S.A. El-Dahshan, et al., Computer-aided diagnosis of human brain tumor through MRI: A survey and a new algorithm, Expert Systems with Applications 41 (2014), 5526-5545.

[2] N. Ganesan, Application of Neural Networks in Diagnosing Cancer Disease Using Demographic Data, vol. 1(26), pp. 76-85, (2010).

[3] Georgiadis, P., Kostopoulos, S., Cavouras, D., Glotsos, D., Kalatzis, I., Sifaki, K., Malamas, M., Solomou, E., and Nikiforidis, G. (2011). Quantitative combination of volumetric MR imaging and MR spectroscopy data for the discrimination of meningiomas from metastatic brain tumors by means of pattern recognition. Magnetic resonance imaging, 29(4):525-35.

[4] D.A. Dahab, S.S.A. Ghoniemy, G.M. Selim, Automated Brain Tumor Detection and Identification Using Image Processing and Probabilistic Neural Network Techniques. International Journal of Image Processing and Visual Communication ISSN2319-1724 Volume 1, Issue 2, October 2012.

[5] Sumitra, N., Rakesh kumar saxena, "Brain tumour classification using Back Propagation Neural Network", International journal of Image, Graphics and Signal Processing, 2013, 2, PP.45-50.

[6] Swapnali Sawakare and Dimple Chaudhari, "Classification of Brain Tumor Using Discrete Wavelet Transform, Principal Component Analysis and Probabilistic Neural Network," International journal for research and emerging science, vol-3 November-2014

[7] Pan, Y., Huang, W., Lin, Z., Zhu, W., Zhou, J., Wong, J., Ding, Z., 2015. Brain tumor grading based on neural networks and convolutional neural networks. In: Conf Proc IEEE Eng Med Biol Soc. pp. 699-702 
[8] T. Liu, C. Chen, X. Shi, C. Liu, IEvaluation of Raman spectra of human brain tumor tissue using the learning vector quantization neural network," Laser Phys. 26, 055606 (2016).

[9] Rani, N., \& Vashisth, S. (2017). Brain Tumor Detection and Classification with Feed Forward BackProp Neural Network. arXiv preprint arXiv:1706.06411

[10] Heba Mohsen et al, "Classification using Deep Learning Neural Networks for Brain Tumors", Future Computing and Informatics, pp 68-71 (2018).

[11] Thejaswini, P., Bhat, B., Prakash, K.: Detection and classification of tumour in brain MRI. Int. J. Eng. Manufact. (IJEM) 9(1), 11-20 (2019).

[12] F. Özyurt, E. Sert, and D. Avc1, "An expert system for brain tumor detection: Fuzzy C-means with super resolution and convolutional neural network with extreme learning machine," Medical hypotheses, vol. 134, p. 109433, 2020.

C. author E-mail: ${ }^{1}$ kawtherthabt@uomustansiriyah.edu.iq, 